\title{
Letrônica
}

\section{Araripe Júnior lê a correspondência de Flaubert}

\section{Araripe Júnior reads Flaubert mail}

\author{
Andréa Correa Paraiso Müller ${ }^{\top}$
}

Doutora em Teoria e História Literária pela Universidade Estadual de Campinas (UNICAMP); professora adjunta de Língua Estadual de Ponta Grossa - PR (UEPG): docente do Programa de Mestrado em Linguagem, Identidade e Subjetividade da UEPG.

andrea.paraiso@uol.com.br
RESUMO: As cartas de escritores podem conter informações relevantes sobre concepções de literatura e processos de composição. A correspondência de Flaubert revela muito de sua estética e de seu pensamento sobre a arte. Quando publicada pela primeira vez, em fins do século XIX, contribuiu para a consagração de seu autor. Também entre a crítica brasileira daquele período, essa correspondência colaborou para a formação de uma imagem de Flaubert como escritor extremamente devotado ao estilo. Neste artigo, refletiremos sobre o julgamento crítico que Araripe Júnior fez de Flaubert ao ler a correspondência do romancista.

Palavras-chave: Correspondência; Leitura; Romance.

ABSTRACT: Writers' letters might contain relevant information on literature conceptions and creation processes. Flaubert's mail reveals a lot about his aesthetics his thought about art. When it was published for the first time, at the end of the XIX century, it contributed to the literary consolidation of its author. Also, among the Brazilian critics of the time, this mail cooperated with the formation of an image of Flaubert as a writer who was extremely devoted to the style. In this paper, we propose some reflection on the critical judgment that Araripe Júnior developed about Flaubert when he read this novelist's mail.

KEYWORDS: Mail; Literature; Novel. 


\section{Introdução}

ustave Flaubert manteve, entre 1830 e 1880, ano de sua morte, uma J vastíssima correspondência. A edição publicada na coleção Bibliothèque de La Pléiade (1973-1998) reúne cerca de quatro mil cartas (LECLERC, 2001, p. 10). Entre os correspondentes estão membros da família, amantes (Louise Colet, por exemplo, com quem discutia literatura), amigos, editores e vários escritores, como Tourgueniev, George Sand, Maupassant... Em muitas dessas cartas, Flaubert expõe suas ideias a respeito da arte, sua concepção de literatura e seus procedimentos de criação.

A publicação de parte dessa correspondência já na década de 1880 contribuiu para o processo de consagração de Flaubert que se verificou em fins do século XIX (PHILIPPOT, 2006). O escritor considerado imoral quando da publicação de seu romance de estreia-Madame Bovary (1856) - passou a ser visto por muitos, ao final do Oitocentos, como modelo absoluto de estilo literário (PHILIPPOT, 2006; MÜLLER, 2012). Muitos fatores concorreram para essa canonização do autor de Madame Bovary: a admiração de Zola e seus pares, que tomaram Flaubert, a sua revelia, como precursor do naturalismo; a progressiva mudança nos critérios de avaliação de romances (a crítica de fins do século XIX foi deixando de lado a moral como principal parâmetro de julgamento da prosa romanesca para ater-se à composição do texto) e a divulgação dos processos de escrita de Flaubert e da extrema importância que ele atribuía ao estilo. Tanto artigos de escritores que com ele conviveram, tais como Zola e Maupassant, quanto a publicação de sua própria correspondência difundiram a imagem de um arquiteto do estilo, sempre em busca da palavra exata, do texto perfeito. Francis Lacoste (2008) assinala que à medida que a vida e estética de Flaubert foram-se tornando conhecidas, ele foi sendo progressivamente entendido como um autor "de referência”, um escritor que dedicou a vida a sua obra (LACOSTE, 2008, p. 8).
Essa imagem também difundiu-se no Brasil. Não foram muitos os críticos brasileiros que escreveram sobre Flaubert no século XIX, mas os que o fizeram mencionaram seu quase obsessivo apego ao estilo, sua busca da frase precisa (MÜLLER, 2012), enxergando-o ora como um mestre da linguagem, ora como um torturado pela forma. E a correspondência do escritor, embora não tenha sido traduzida para o português, foi lida por aqui, conforme mostraremos mais adiante.

Neste artigo, refletiremos sobre a leitura de Flaubert feita por Araripe Júnior, um dos críticos mais importantes do Oitocentos brasileiro, comumente enquadrado, ao lado de Sílvio Romero e José Veríssimo, na chamada tríade da crítica realista. Nos textos em que se refere a Flaubert, Araripe demonstra ter lido sua correspondência; os julgamentos que faz a respeito do escritor parecem, em alguns momentos, orientados mais pela leitura das cartas do que da própria obra.

A partir dos textos de Araripe Júnior, refletiremos sobre o papel da correspondência na consolidação da imagem de um Flaubert ao mesmo tempo artífice e mártir da palavra. Imagem esta que se relaciona ao processo de consagração, não apenas do romancista em estudo, mas do próprio gênero romanesco.

\section{A publicação da correspondência de Flaubert na França}

A primeira vez que trechos da correspondência de Flaubert vieram a público foi em setembro de 1880, quatro meses após seu falecimento. 0 escritor Guy de Maupassant divulgou algumas passagens de cartas de seu mestre e amigo no artigo "Gustave Flaubert d'après ses lettres", publicado no jornal Le Gaulois, de 6 de setembro de 1880. Apresentando um Flaubert inteiramente entregue ao trabalho da escrita, Maupassant selecionou passagens de cartas do escritor que reforçavam essa imagem. Transcrevemos 
abaixo alguns dos trechos da correspondência de Flaubert citados por Maupassant em seu artigo:

Seu amigo trabalhou este inverno de uma maneira que nem ele mesmo compreende. Durante os últimos oito dias dormi ao todo dez horas. Só me sustentava à custa de café e de água fria; enfim, estava tomado por uma assustadora exaltação. Um pouco mais, o homem morreria. (FLAUBERT apud MAUPASSANT, 1880, p. 1 - tradução nossa) ${ }^{1}$

Trabalho muito, banho-me todos os dias, não recebo nenhuma visita, não leio nenhum jornal, e vejo com bastante frequência o nascer da aurora (como agora), pois levo meu trabalho madrugada adentro, janelas abertas, em mangas de camisa, e berrando, no silêncio do gabinete, como um energúmeno. (FLAUBERT apud MAUPASSANT, 1880, p. 1 - tradução nossa) ${ }^{2}$

Transcrevendo essas passagens da correspondência de seu mestre, Maupassant inicia o que viria a ser quase um mito: o trabalho de Flaubert, sua obsessiva dedicação à elaboração da linguagem e à busca da forma prefeita. Quatro anos depois, a editora Charpentier publicou as cartas de Flaubert à escritora George Sand, precedidas de um estudo assinado por Maupassant (LECLERC, 2001, p. 3).

A primeira edição da correspondência geral de Gustave Flaubert veio à luz entre 1887 e 1893. A primeira, a segunda e a terceira séries foram publicadas pela editora Charpentier em 1887, 1889 e 1891, respectivamente; a quarta série de cartas foi editada por Charpentier e Fasquelle, em 1893 (CLÉROUX, 2013). As quatro séries reuniram 809 cartas. Segundo Yvan Leclerc (2001, p. 3), o texto é "lacunar" e "inexato". Entretanto, parece ter sido suficiente

1 “Votre ami a travaillé cet hiver d'une façon qu'il ne comprend pas lui-même. Pendant les derniers huit jours j'ai dormi en tout dix heures. Je ne me soutenais plus qu'à force de café et d'eau froide; bref j'étais en proie à une effrayante exaltation. Un peu plus, le bonhomme claquait."

en proie a une effrayante exaltation. Un peu plus, le bonhomme claquait." "Je travaille beaucoup, je me baigne tous les jours, je ne reçois aucune visite, je ne lis aucun journal, et je vois assez régulièrement lever l'aurore (comme présentenent), car je pousse ma besogne fort avant comme un énergumène." para divulgar, entre a crítica de fins do Oitocentos, as teorias de Flaubert sobre a arte e sobre a escrita literária.

Didier Philippot, pesquisador que compilou, na década passada, toda a crítica a respeito de Flaubert produzida desde o lançamento do romance de estreia, em 1856, até os primeiros decênios do século XX, afirma que o momento máximo de "sacralização" do nome do autor de Madame Bovary ocorreu na virada do século XIX para o seguinte (PHILIPPOT, 2006, p. 97). Segundo o pesquisador, um dos principais atores desse processo de consagração de Flaubert foi o escritor e crítico Antoine Albalat, que, em textos sobre a composição literária, exaltou a dedicação do romancista de Croisset à linguagem, ressaltou seu esforço de aperfeiçoamento do estilo. Albalat opunha o trabalho árduo de Flaubert ao que ele chamava de "estilo fácil" dos escritores que redigiam sem cuidado e aprimoramento. E era justamente na correspondência que o crítico se apoiava para salientar a entrega do escritor às angústias da elaboração formal:

Flaubert encarnou o trabalho. [...]

Todos os grandes escritores trabalharam. Este morreu na tarefa.

É preciso ler na sua correspondência as torturas desse gigantesco esforço. [...]

Não transcreveremos aqui as quotidianas e dolorosas confissões de Flaubert. Os testemunhos de sua correspondência encheriam volumes. 0 que é preciso reter são os princípios gerais de seu método. [...]

Durante vinte anos, Flaubert passou as noites e uma parte de seus dias em seu escritório. Levava cinco anos em média para fazer um livro. Jamais teve confiança na inspiração. (ALBALAT, 1902 apud PHILIPPOT, 2006, p. 703-704 - tradução nossa) ${ }^{3}$

3 "Flaubert a incarné le travail. [...]

Tous les grands écrivains ont travaillé. Celui-là s'est tué à la tâche.

Il faut lire dans sa correspondanceles tortures de ce gigantesque effort [

Nous ne transcrirons pas ici les quotidiennes et douloureuses confessions de Flaubert Les aveux de (des volumes. Ce qu'il faut retenir ce sont les principes généraux de sa sa correspond

. Flaubert passa les nuits et une partie de ses journées à son bureau. Il mettait cinq ans en moyenne pour faire un livre. Il n'eut jamais confiance dans l'inspiration." 
Era, pois, na correspondência, então recentemente publicada, que Albalat encontrava o que ele interpretava como sendo os princípios literários de Flaubert. Era por meio dessa correspondência que se tornava público o longo tempo dedicado pelo escritor à redação de seus romances. O crítico servia-se, portanto, da correspondência, para interpretar e julgar o autor.

Albalat não foi o único a fazer isso. As teorias de Flaubert e os seus métodos de trabalho expostos em suas cartas provocaram impacto na crítica de fins do século XIX e início do XX; não foram poucos os escritores e críticos que, ao escreverem sobre o autor, levaram em conta sua correspondência, tomando-a, muitas vezes, como base para a apreciação da obra. Houve até mesmo quem enxergasse a correspondência como prova de que Flaubert não possuía um talento natural, uma vez que, para escrever bem, precisava trabalhar exaustivamente. Suas cartas seriam a demonstração de que, ao escrever de maneira espontânea, o autor não alcançava a mesma qualidade de seus textos literários. Foi o caso do famoso crítico Albert Thibaudet, para quem o estilo da correspondência continha banalidades, diferentemente das cartas de Chateaubriand:

Mas enfim isso deveria bastar para fazer-nos admitir que Flaubert não é um grande escritor de raça e que o pleno domínio verbal não lhe era dado em sua própria natureza. E essa ideia se confirma quando lemos suas Obras de juventude e sua Correspondência. Evidentemente, elas devem nos interessar muito pelas informações que nos trazem sobre a vida interior e a formação das ideias de Flaubert [...] mas o estilo das Obras de juventude [...] é de uma insignificância absoluta, e a Correspondência, se nos diverte por tantas páginas de verve, pulula de banalidades que nos mostram que Flaubert tinha necessidade de segurar as rédeas de sua pena para tirar dela boa prosa. (THIBAUDET, 1939, p. 73 - tradução nossa). ${ }^{4}$

\footnotetext{
“Mais enfin cela devrait suffire à nous faire admettre que Flaubert n'est pás um grand écrivain de race et que la pleine maîtrise verbale ne lui était pas donnée dans sa nature même. Et cette idée se

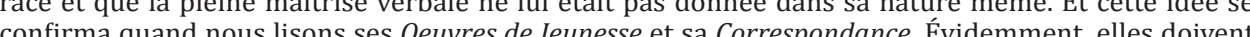
作 . formation des iderriance
}

No artigo a que nos referimos, Thibaudet retomava uma questão polêmica colocada por outro crítico, Louis de Robert: "Flaubert sabia escrever?" (THIBAUDET, 1939, p. 72 - tradução nossa.) Para Thibaudet, essa questão fora deixada de lado, obscurecida. Na opinião do crítico, havia-se formado uma imagem de Flaubert a partir do que ele mesmo dissera sobre si em suas cartas, e muitos o admiravam justamente por essa imagem que ele próprio transmitira, sem questionar se ele realmente escrevia bem ou não: “[...] ela [a questão da boa escrita de Flaubert] foi talvez obscurecida por aqueles que louvaram Flaubert pelas qualidades que ele quis ter mais do que por aquelas que ele realmente teve" (THIBAUDET, 1939, p. 72-73 - tradução nossa). ${ }^{5}$

Embora se tenha equivocado ao comparar o estilo das cartas com o da obra literária, Thibaudet demonstra perspicácia ao perceber que advém da leitura da correspondência uma certa mistificação da figura de Flaubert.

Em muitas das cartas, Flaubert expunha o sofrimento da escrita. Na passagem a seguir, retirada de uma carta ao amigo pessoal Louis Bouillet, datada de 7 de junho de 1855, o autor referia-se à redação de Madame Bovary:

Vou bem lentamente. Tenho feito um esforço de cão. Acontece-me de suprimir ao cabo de cinco ou seis páginas, frases que me exigiram dias inteiros. Não consigo ver o efeito de nenhuma sem que esteja terminada, arrematada, polida. (FLAUBERT, 1891, p. 21 - tradução nossa) ${ }^{6}$

Ao inciar a composição de seu último romance, Bouvard et Pécuchet, Flaubert previu entre três e quatro anos para concluir, como se pode observar nesta carta a Edmond de Goncourt, de 22 de setembro de 1874:

No meu retorno aqui no mês de agosto, finalmente comecei meu romance, o qual vai me demandar três ou quatro anos (é sempre isso o necessário).

5 "Flaubert savait-il écrire?"

6 "Je vais bien lentement Je me donne um mal de chien. Il m'arrive de supprimer, au bout de cinq ou six pages, des phrases qui Je me donne ú me jour dés d' pages, des phrases qui mont demandé des joun 
Achei de início que não podia mais escrever uma linha. 0 começo foi duro. Mas enfim, vai indo, ou pelo menos, melhorou. (FLAUBERT, 1893, p. 203 - tradução nossa) ${ }^{7}$

Na verdade, o romance ocupou muito mais tempo: a redação de Bouvard et Pécuchet foi interrompida pela morte de Flaubert, em maio de 1880.

As cartas permitiram, pois, aos leitores e críticos, descobrir a cronologia da redação das obras, bem como conhecer os métodos e as convicções de Flaubert. E isso ainda no século XIX, bem pouco tempo após a morte do escritor. No momento em que os critérios de avaliação crítica de romances deixavam de lado os parâmetros morais para valorizar a feitura do texto, a obsessão flaubertiana pelo trabalho do estilo propagada pela leitura de sua correspondência veio alimentar novas concepções de escrita.

\section{As referências à correspondência de Flaubert na imprensa brasileira}

A correspondência de Flaubert tardou a ser traduzida no exterior. Segundo Gilles Cléroux (2013, p. 4), a primeira tradução para a língua alemã data de 1906. Na Inglaterra, uma seleção de cartas de Flaubert foi publicada traduzida apenas em 1954 (CLÉROUX, 2013, p. 4).

Não encontramos referência a traduções para a língua portuguesa, mas letrados brasileiros do final do século XIX tomaram conhecimento dessa correspondência, e muitos demonstraram ter lido ao menos parte dela. Além disso, artigos estrangeiros mencionando-a e ressaltando a reputação que o escritor adquirira, sobretudo após a publicação das cartas, de mártir do estilo, foram veiculados na imprensa brasileira.

\footnotetext{
"À mon retour ici au mois d'août, j'ai enfin commencé mon roman, lequel va me demander trois ou quatre ans (c'est toujours ça de bon). Je crus d'abord que je ne pouvais plus écrire une ligne. Le début a été dur. Mais enfin, ça marche ou du moins ça va mieux."
}

Em 9 de outubro de 1892 (com continuações em 30 de outubro e 6 de novembro do mesmo ano), oJornal do Commercio do Rio de Janeiro reproduziu um artigo que havia sido publicado dois meses antes pela revista mensal estadunidense Harper's new monthly magazine. 0 autor era o correspondente de Paris da revista, Theodore Child, um inglês avesso ao naturalismo de Zola. Seu artigo iniciava-se salientando o esgotamento da escola naturalista e prosseguia sublinhando o prestígio dos irmãos Goncourt e de Flaubert (CHILD, 1892, p. 2). No entanto, embora reconhecesse a importância do autor de Salammbô nas letras francesas daquele momento, criticava-lhe a preocupação excessiva com a forma. Para o articulista, tratava-se de uma verdadeira "doença do estilo", um "modismo" que se propagar na França a partir do próprio Flaubert e dos adeptos da doutrina da "arte pela arte". E, para demonstrar o quanto esse "modismo" era negativo e torturante, Child fazia alusão aos "gritos de dor e desespero" que Flaubert manifestava em sua correspondência. Assim como vários críticos franceses, o correspondente da Harper's apoiava-se nas cartas publicadas para conhecer e julgar o método flaubertiano. E ajudava a propagar, fora da França, a imagem, já tão consolidada naquele país, de um Flaubert torturado pela forma.

Ainda naquele ano de 1892, em 16 de dezembro, o Jornal do Commercio, mesmo periódico que reproduzira o artigo de Theodore Child, publicou, na coluna "Chronica estrangeira", uma carta de Flaubert a sua amiga de longa data Laure de Maupassant, mãe de Guy de Maupassant. O jornal não mencionava quem teria traduzido a carta, levando-nos a crer que possa ter sido o próprio colunista, que assinava sob o pseudônimo de Alter Ego. Escrita em 23 de fevereiro de 1873, a carta, apesar de pessoal, continha muitas considerações sobre literatura. Flaubert mostrava-se decepcionado com o mercado literário daquele momento. Seu último romance, $A$ educação sentimental, de 1869, amargara um retumbante fracasso, e o autor pensava em não mais publicar seus textos. Causava-lhe repulsa, particularmente, a "literatura militante", 
mais voltada à defesa de uma ideia do que à elaboração artística: “Estou tão enojado de tudo e particularmente da literatura militante, que renunciei a publicar o que escrevo. A vida está sendo pouco agradável para as pessoas de gosto" (FLAUBERT, 1873 in ALTER EGO, 1892, p. 2).

Conquanto tenha expressado a intenção de deixar de publicar, publicaria A tentação de Santo Antão já no ano seguinte, 1874. Seu desencanto com a literatura de seu tempo e sua aversão à sociedade burguesa não o impediram de incentivar a vocação literária de Maupassant. Advertia, porém, que o culto à arte importava mais do que o sucesso:

Apesar disto, deves animar a vocação que teu filho mostra para os versos, porque é uma nobre paixão, porque as letras consolam de muitos infortúnios e porque talvez venha a ter talento, quem sabe? [...]

Com o tempo adquirirá originalidade, um modo individual de ver e de sentir (porque tudo está nisso!). Quanto ao resultado, ao sucesso, que importa! 0 principal neste mundo é conservar a alma em uma região alta, longe das lamas burguesas e democráticas. 0 culto da arte produz o orgulho; ora, nunca se possui orgulho demais. Tal é a minha moral. (FLAUBERT, 1873 in ALTER EGO, 1892, p. 2)

A carta revelava um pouco da personalidade de Flaubert: seu amor pela arte e sua rejeição a submeter-se ao gosto burguês. O colunista Alter Ego informou, ao apresentá-la, que dentro de poucos dias deveria sair em volume, na França, a quarta série da correspondência de Flaubert. Referia-se, sem dúvida, à edição de Charpentir e Fasquelle, cujo quarto tomo foi publicado em 1893.

A transcrição da carta, traduzida para o português, na coluna "Chronica estrangeira" possibilitou aos leitores do Jornal do Commercio (e não somente aos homens de letras, conhecedores da língua francesa) o acesso a pelo menos uma pequena parte da correspondência do escritor francês.

Portanto, ainda que as cartas de Flaubert não tenham tido edição em língua portuguesa, repercutiram no Brasil. E a visão de um Flaubert entregue ao trabalho intenso em busca do aperfeiçoamento do estilo, tão difundida na crítica francesa, também ressoou em comentários de nossos letrados.

\subsection{A leitura de Araripe Júnior}

Entre a crítica brasileira oitocentista, Araripe Júnior foi certamente o que mais referências fez a Flaubert. No artigo "Enfermidades estilísticas da nova geração", publicado originalmente em 1886, transmitiu do autor de Madame Bovary a imagem de um escritor brilhante, cujo "estilo sublime e torturado" originava-se do sofrimento, da relação doentia do artista com sua própria arte. Essa imagem, que, como vimos, estava tão difundida na França, advinha dos textos que os discípulos de Flaubert, marcadamente Maupassant e Zola, haviam escrito louvando o trabalho de seu mestre, e da correspondência do autor, em que este expunha seus métodos e suas teorias. Ora, em 1886, quando Araripe Júnior publicou seu artigo no periódico $A$ Semana, a correspondência geral de Flaubert ainda não havia sido publicada (conforme informamos neste trabalho, o primeiro tomo foi lançado em 1887). No entanto, já haviam sido divulgadas cartas esparsas. Araripe inicia seu artigo citando um excerto da correspondência de Flaubert para fundamentar sua interpretação:

"Extraordinária coisa", diz Flaubert, "a dose de pouca fé na felicidade com que nasci! Logo em criança tive um pressentimento completo da vida. Senti como que um cheiro nauseabundo de cozinha escapando-se de um cano de esgoto. Não é preciso já ter comido para saber que é para causar vômitos." Nestas palavras encontra-se resumida toda a vida literária doentia e nervosa do infeliz autor da Bovary. Estilo sublime e torturado... mas a custa de quanto sofrimento! (ARARIPE Jr., 1963, p. 432)

A passagem citada por Araripe, faz parte de uma carta de Flaubert a Maxime Du Camp, escrita em 7 de abril de 1846 (FLAUBERT, s.d.p., p. 131). Araripe a seleciona para melhor classificar o missivista entre as "enfermidades estilísticas" de que era objeto o artigo. 
Embora desaprovasse o apego "doentio" de Flaubert à elaboração formal, sua entrega torturante à busca da perfeição do estilo, louvava-lhe o talento. $\mathrm{O}$ romancista teria, segundo Araripe, demonstrado genialidade e "brilhantismo" ímpares na criação da personagem Bovary. Ou seja, o crítico aprovava o que se podia julgar pela leitura da obra e reprovava o que só se podia conhecer pela leitura da correspondência ou dos escritos de outros críticos. Louvava o talento de Flaubert em sua obra literária e criticava seu temperamento expresso nas cartas.

Araripe desaprovava, ainda, os imitadores de Flaubert, sobretudo os escritores estrangeiros (provavelmente referia-se a portugueses e brasileiros), que procuravam reproduzir os procedimentos literários do francês em contextos por demais distintos:

No meio de tudo isto, há, porém, uma coisa que sempre sobrenada e não mente nunca. É o talento: é o gênio literário. Pouco importa que Flaubert, inspirando-se na sua índole e na observação que o seu gênio especial lhe indicava, produzisse um tipo agonizante como o da infeliz Bovary. Ele o fez com brilhantismo nunca visto: é quanto basta; mas o que não é curial é que procurem imitar suas intenções orgânicas. Pouco importa que Zola, encontrando afinidades entre a sua e a índole daquele mestre, entrasse triunfante na arena neocrítica, dandose como musa a indignação e a vingança. Zola fê-lo a propósito, no tempo e no lugar aonde a voz podia ser legitimamente ouvida e reverenciada. 0 êxito o justifica; mas o que não se justifica, é que, fora desse meio, tentem vibrar uma corda à marselhesa, só compreensível pelo diletantismo do povo de cujas fibras foi construído o instrumento e que o mestre se exercitava. (ARARIPE Jr., 1963, p. 432)

Dois anos depois, o crítico expressou-se novamente sobre Flaubert, desta vez no interior de um longo artigo dedicado aos romances A Terra, de Zola, e $O$ homem, de Aluísio Azevedo. Suas considerações acerca do surgimento de Zola no universo literário do século XIX revelavam uma concepção evolucionista da literatura, condizente, aliás, com o espírito do período. Comparou o impacto do surgimento de Zola na literatura ocidental à surpresa dos antigos romanos ao avistarem, pela primeira vez, um elefante. 0 espanto, nos dois casos, devia-se à "transição rápida" e ao "desconhecimento das formas intermédias". De acordo com Araripe, Zola provocou tamanho choque porque seus contemporâneos não haviam dado a devida atenção à transição operada por Balzac, Stendhal, Champfleury e Flaubert:

A aparição de E. Zola no mundo literário, pode-se afirmar que trouxe impressão bem semelhante àquela [o elefante visto, pela primeira vez, pelos romanos] Estávamos todos imbuidíssimos de V. Hugo, de Lamennais, de Quinet, de Dumas e de outros pouco houvéramos percebido as formas intermédias de Balzac, Champfleury, Stendhal, Flaubert; quando, portanto, a belfa destes tipos se hipertrofiou na larga tromba do autor do Assommoir, todo o sossego literário desapareceu, e o susto manifestou-se pelas formas mais exageradas que já puderam inventar a preguiça e a mediocridade. (ARARIPE Jr., 1960, p. 27-28)

O crítico foi traçando um rápido panorama da história do romance, desde as narrativas míticas, para explicar que as formas narrativas que se apresentavam tão aperfeiçoadas em todo um rol de escritores de renome naquele século, foram o resultado de uma longa evolução:

Ora, as formas que hoje encontramos tão aperfeiçoadas em Flaubert, em Dickens, em Farina, em Zola, em Turguenev, em Bret Harte, em Dostoievski, em Tolstoi, em Marion Crawford, em G. Eliot, em E. de Queirós, em Bourget, em A. Azevedo, não apareceram arbitràriamente, nem foram inventadas pelos artistas que lhes deram direito de cidade; nebulosas em princípio, como expresão vaga das aspirações das raças, essas formas foram se condensando a pouco e pouco, durante um largo período, em que as literaturas não tinham órgãos cultos; e só quando a renascença das letras antigas pôde habilitar poetas e literatos a escreverem com apuro e com a experiência da arte adquirida anteriormente, foi que conseguiram esplender as obras do século XIV e XV. (ARARIPE Jr., 1960, p. 29) 
A lista de nomes que Araripe abriu com Flaubert soa como uma espécie de cânone dos escritores de tendências realistas e naturalistas. $O$ crítico não via Flaubert como um naturalista, mas como um dos intermediários entre a escola romântica e o naturalismo.

Se dois anos antes Araripe criticara a "enfermidade" de Flaubert, sua dedicação doentia à elaboração formal, creditava-lhe agora o mérito de ter introduzido no romance "o verdadeiro sentimento da forma":

Sem as pretensões de Balzac, acaso dotado de uma envergadura menos resistente, Flaubert, que andou mostrando sua potência imaginativa em obras de gênero diverso, como a Tentação de Santo Antônio e a Salammbô, teve a felicidade inaudita de introduzir no romance o verdadeiro sentimento da forma. Não há quem não conheça as suas teorias sobre a arte. A sua correspondência particular, hoje reunida em volume, constitui a história mais proveitosa que conheço, para quem queira saber o que é um temperamento artístico, e quais as leis que presidem à formação de uma obra de arte.

Tôda a vida literária do autor da Bovary pode-se reduzir à seguinte fórmula: - adaptação de um temperamento, pelo esfôrço consciente, pela paixão e pela raiva artística, ao fato. 0 fato é o fato; mas o fato é sempre novo e não esgota; e a atenção impertérrita de um autor pode dêle tirar mundos infinitos de expressão. (ARARIPE Jr., 1960, p. 40)

O trecho citado demonstra que Flaubert era, naquela época, bastante conhecido, não apenas por suas obras literárias, mas também por seu pensamento a respeito da arte ("Não há quem não conheça as suas teorias sobre a arte."). A publicação de sua correspondência, além de difundir suas ideias, tornara-o ainda mais célebre. No ano em que Araripe Júnior escreveu o artigo em questão, 1888, a primeira série das cartas de Flaubert já havia sido publicada pela editora Charpentier, e seu pensamento sobre a escrita já era, pois, conhecido dos literatos e críticos. Araripe Júnior não se ateve, nesse artigo, à "enfermidade" do estilo que ele identificara em Flaubert a partir de uma possível primeira leitura de cartas esparsas. Ele agora apoiava-se em um número bem maior de cartas para enxergar a obra a partir das teorias de seu autor. Referiu-se a Flaubert como um "grande mestre”, um autor de prestígio junto à geração que o sucedeu. $\mathrm{O}$ romancista normando teria operado uma revolução na literatura ao fazer da arte um "fenômeno consciente":

Pois bem, Flaubert gastou a parte mais importante de sua vida a intensificar-se no fato histórico de Cartago e no fato fisiológico da infeliz adúltera. 0 exemplo foi tremendo, porque até então nenhum escritor conseguira provar o que êle conseguiu, isto é, _ que a atenção e a alucinação artística podiam substituir as máquinas e os artifícios, retirando do romance todod o supérfluo, dando à obra de arte um caráter espontâneamente simples, justamente quando as literaturas ocidentais enfrentavam os assuntos mais complexos. Mas é que o grande mestre descobrira na arte a lei do menor esfôrço e, despido de qualquer aparato científico, chegara ao resultado mais importante que, quanto a mim, se tem produzido na história literária moderna: falo da redução da função artística a um fenômeno perfeitamente consciente. É esta a obra capital de Flaubert; e só depois de estudá-la atentamente se pode chegar a compreender tôda a extensão da revolução por êle operada, o prestígio que exerceu sôbre a geração atual, a impecabilidade dos seus livros e a singularidade de sua doutrina. Sob êste ponto de vista, não há dúvida que a obra do autor da Bovary foi mais benéfica que a de Balzac, de quem o separava uma diversidade de temperamento colossal (ARARIPE Jr., 1960, p. 40).

Araripe qualificou Flaubert como "o Colombo da arte do século XIX", ou seja, alguém que havia realizado um feito na história do romance: despira o gênero de todos os elementos supérfluos, presentes até mesmo nos textos de Balzac, e fundara-o na observação. Flaubert era inovador à medida que rompia com os artifícios para dar à arte um caráter simples. Ocupava, na visão do crítico, um lugar superior ao de Balzac, uma vez que aperfeiçoara os procedimentos de seu antecessor:

Flaubert foi o Colombo da arte do século XIX; pelo menos, foi o primeiro que, de um modo concreto, soube mostrar em que consistia o subjetivismo artístico a a relatividade do real. Com uma impulsão destas, é fácil de prever quanto não se lhe tornariam antipáticas certas excrescências, que Balzac acumulou mesmo nos seus melhores livros. Desde que o romance, como um todo orgânico, fundava-se num esquema e desenvolvia-se no espírito 
do autor, à proporção que se iam aplicando os processos de observação, por prolificações ou estratificações sucessivas, era fora de dúvida que uma obra tal não podia suportar o supérfluo, muito menos um corpo estranho, e arrojaria, naturalmente, para fora de si todos êsses elementos perturbadores, desde que o assunto fôsse manuseado por escritor de raça. Ora, a revisão que Flaubert operou nas formas acentuadas por Balzac, nas suas obras clássicas, consistiu exatamente na exclusão do charlatanismo que, de ordinário, é a lepra dos espíritos abundantes demais e que a natureza não dotou do que se pode chamar o registro do talento. (ARARIPE Jr., 1960, p. 40-41)

Flaubert exercera, na opinião de Araripe, grande influência sobre Zola:

A reação operada pelo método de Flaubert sôbre o chefe do naturalismo atual é mais considerável do que se pensa. Os artistas que mais influem sobre nós são precisamente aquêles que, constituindo caracteres opostos ao nosso, conseguem impressionar-nos de modo mais profundo. Ora, Zola nasceu com um temperamento violento; e tôdas as suas disposições naturais o impeliam para as composições largas, amplas, de perspectivas longínquas. Ao contrário disso, o autor da Bovary imitava os seus assuntos e nunca saiu do pequeno grupo da família.

Essa moldura não podia suportar as imensas telas que se esboçavam no espírito do classificador dos Rougon-Macquart.

Acresce a isto que, em tôrno dêle, ainda existiam os Goncourt, e Daudet, que o ameaçavam, _ ao primeiros com a sua crescente limpidez de estilo e exatidão de partes, e o segundo com um sentimento do real capitoso, larvado de um histerismo adorável, uma forma cintilante, mágica, porejante de íris. Essa extraordinária pressão do que se pode chamar o espólio de Flaubert, obrigou-o a formular o seu processo, e explodiu na teoria célebre do romance experimental. (ARARIPE Jr., 1960, p. 42-43)

Segundo a interpretação de Araripe, Flaubert influenciara o pensamento de Zola sobre a literatura não apenas de maneira direta, mas também indiretamente, por meio dos irmãos Goncourt e de Alphonse Daudet, todos os três herdeiros do autor da Bovary. O crítico situava Flaubert, pois, na base das transformações literárias realizadas pelo naturalismo; era ele a principal fonte na qual haviam bebido os adeptos das tendências naturalistas. A "limpidez de estilo" dos Goncourts e o "sentimento do real capitoso" expresso pela "forma porejante" de Daudet seriam parte da herança de Flaubert.

A visão de Flaubert que Araripe transmitiu nesse texto é absolutamente positiva. $\mathrm{O}$ escritor foi mostrado como um marco na literatura francesa, um criador e teórico que rompera com antigos procedimentos e inaugurara uma nova maneira de conceber o romance e a literatura.

Pouco tempo depois, no entanto, em um artigo sobre Raul Pompeia publicado entre dezembro de 1888 e fevereiro de 1889, Araripe voltou a criticar os suplícios de Flaubert na elaboração artística. Salientou os sofrimentos que o escritor impôs a si mesmo para sufocar sua índole subjetiva e compor romances objetivos. A "clarividência subcerebral", ou a convergência das forças do artista para explorar, de forma consciente, "os mais obscuros problemas" ao mesmo tempo em que havia gerado, segundo Araripe, o humour inglês, produzira, na literatura francesa, uma "doença de consciência", que levara à "epilepsia literária" de Flaubert e dos Goncourts:

Nem todos os escritores de procedência francesa têm alcançado temperar essa faculdade mal-assombrada com uma dose regular de gauloiserie, como vemos suceder com Alphonde Daudet quando nos transfunde na alma êsse seu inimitável Dom Quixote gaulês, o Tartarin de Tarascon. Bastam, porém, os exemplos de Flaubert e dos Goncourt para que nos convençamos de quanto o exercício de tais fôrças cerebrais pode aproximar certos escritores da epilepsia literária, afastando-os da ironia equilibrada dos psicólogos anglo-saxônios. A psicologia dessa classe de artistas pode, em última análise, resumir-se nestas palavras: _ o pânico do belo.

Sabemos dos sofrimentos que Flaubert amargou, por pretender desviar-se da sua índole subjetiva, e quantos anos de tortura, de crucificação, lhe custaram os romances objetivos que produziu. Madame Bovary e a Salammbô tiveram uma gestação quase extra-cerebral. Sem embargo disto, manuseie-se a sua Correspondência, e a cada instante se reconhecerá que o pânico do belo era o propulsor do seu talento. Não há carta sua em que se não encontre referências mais ou menos vagas à antipatia que a vida de ação lhe causava, quando não se tratava de uma ação violenta (forcenée). Invade-o constantemente o terror das coisas más, como um nevoeiro; perde-o, suplicia-o a angústia do 
bom gôsto. São quase que diárias as suas rupturas com o mundo exterior e os seus elances para um vida só dedicada à idéia do sibi constat de Horácio; a cada instante surgem as exclamações de que a alma possui a faculdade de enlanguecer-se pelo sofrimento, chegando por aí a capacidades prodigiosas; e logo adiante o baque do desânimo, as desolações das dificuldades artísticas. E, como complemento de tudo, _ a deliciosa tortura do ideal aceito, o encêrro na arte, o ascetismo poético, a satisfação das aspirações de brâmane ocidental (ARARIPE Jr., 1960, p. 165)

O julgamento que Araripe fez de Flaubert, sobretudo nesse artigo, parece basear-se muito mais sobre a correspondência do escritor do que sobre sua obra literária. A imagem de um Flaubert afastado da sociedade, preocupado apenas com a perfeição formal, torturado pelas agruras da escrita vem de suas cartas, em que confessava as dificuldades da criação artística e os sofrimentos que ela lhe impunha. Araripe julgava menos a literatura de Flaubert do que suas teorias sobre a arte literária.

Em 1905, o crítico publicou no Almanaque Brasileiro Garnier um pequeno artigo intitulado "Flaubert", em que apresentou uma avaliação sucinta da obra e do pensamento do autor. Ao contrário da análise positiva que fizera do escritor em 1888, Araripe expressava agora uma opinião negativa a respeito de Flaubert, contrapondo-se a textos críticos que haviam sido lançados na França naqueles últimos anos, como o ensaio de Émile Faguet, de 1899.

O artigo de Araripe iniciava-se chamando a atenção para o que ele considerava o maior defeito de Flaubert, o pessimismo superficial:

O grande defeito dêsse escritor foi um pessimismo epidérmico. Digo epidérmico, porque êsse pessimismo não tinha por base uma concepção filosófica, nem o conhecimento do que há de transcendente na alma humana. O pessimismo de Flaubert resultava da fraqueza de caráter, fato que se refletiu em tôda a sua obra (ARARIPE Jr., 1966, p. 165).

Ao iniciar apontando o que seria o "grande defeito" de Flaubert, o crítico já adiantava o tom negativo do restante do artigo. Os elogios anteriormente dirigidos ao "Colombo da arte do século XIX" cediam lugar a duras críticas. Araripe condenava o suposto desinteresse do escritor pelas questões sociais, e opunha-o a uma lista de grandes escritores que abordaram temas políticos e sociais :

Diz Faguet que Flaubert era produto do orgulho e da timidez. Concordo em parte. É, todavia, indispensável que a tal fenômeno se adicione a sua incapacidade quase completa para os trabalhos de síntese social; faculdade que E. Zola possuía em grande escala.

Não há uma só página de Flaubert em que se pressinta preocupação sôbre os destinos das sociedades, nem ainda na Tentação de Santo Antônio. Restaurando a vida de Cartago, na Salammbô, escapou à sua curiosidade justamente aquilo que, de modo mais soberano, atrairia espíritos como Goethe, Michelet, Mommsen, Schiller, Taine, Swinburne.

Daí as lacunas de sua obra; e também a limitação do seu realismo aos caracteres médios e aos aspectos baixos da vida quotidiana.

É bastante conhecida a sua repugnância pela política e pelo estudo dos caracteres, em que mais se acentuou o gênio de Shakespeare (Ricardo III, Júlio César, Henrique IV, Macbeth), _os ambiciosos de dominação. Sob êste ponto de vista, que mesquinha figura é a de Amilcar, pintado na Salammbô! (ARARIPE Jr., 1966, p. 165)

Se no artigo de 1888 Araripe incluíra Flaubert em um rol de grandes escritores do século XIX, ele agora o excluía de um outro rol de grandes escritores, de diferentes épocas, que trataram de questões políticas e sociais. Opor esses escritores a Flaubert servia como um argumento contra este último, contra a sua suposta falta de preocupação com "os destinos das sociedades".

O crítico não desmentiu sua observação anterior (do artigo de 1888) de que Flaubert despira o romance dos supérfluos. Reafirmou que o artista suprimira de seus livros os juízos e perorações dos românticos para por em cena personagens agindo diante do leitor. No entanto, esse procedimento, aparentemente objetivo, era visto por Araripe como indício de subjetividade, uma vez que se originava da própria psicologia do autor: 
É certo que Flaubert suprimiu sistemàticamente de seus livros o vêzo dos românticos de emitir juízos diretos sôbre os personagens, expendendo opiniões arbitrárias sôbre o caráter de cada um.

Ao contrário disto, êle os colocava em cena como se fôssem livres, encadeava lògicamente os acontecimentos, fazia-os falar de acôrdo com a natureza dêles e apresentava-os, no ato de se determinarem, coagidos por motivos inelutáveis.

Tudo isto parece o que há de mais objetivo na exposição da vida real. Pois não é. A alma do artista era a causa única dessa sensação de realismo. Tais personagens são puros produtos de uma evolução lógica realizada ùnicamente no cérebro do autor. (ARARIPE Jr., 1966, p. 165)

O já quase mito, tão propagado naquele final de século, principalmente pela publicação da correspondência do autor, de um Flaubert monge das letras, dedicado à arte e torturado por essa entrega, parece ter contribuído para a leitura que Araripe Júnior fez da obra do romancista. A preocupação com a elaboração formal, aliada a declarações contidas na correspondência, passou a ser entendida como indiferença às questões político-sociais. 0 desencanto de Flaubert manifestado em suas cartas, que já chegara a ser citado por Araripe no artigo de 1886 aqui mencionado, parece ter direcionado o foco de certas leituras críticas para o pessimismo das obras do escritor.

\section{Considerações finais}

Assim como tantos críticos franceses, o brasileiro Araripe Júnior também acabou por orientar sua leitura de Flaubert pela correspondência do autor. Desde o primeiro artigo em que menciona o escritor, sua interpretação não se fixa apenas na obra literária, mas deixa-se influenciar pela correspondência.

Segundo Luiz Roberto Cairo, era comum que Araripe mudasse de opinião a respeito de obras e autores de um artigo para outro:
Vale observar que o simples fato de Araripe Júnior publicar seus ensaios em jornais e revistas, em períodos relativamente longos, devia proporcionar-lhe um constante repensar de pontos de vista. Isto talvez explique a variação de enfoque de um mesmo problema, muitas vezes, num mesmo trabalho (CAIRO, 1996, p. 33).

No caso de sua interpretação de Flaubert, o repensar de seus pontos de vista parece estar relacionado à leitura das cartas do escritor, que revelavam posicionamentos do autor que o crítico e ensaísta não conseguia deixar de considerar em sua apreciação da obra.

O caso da leitura de Araripe é representativo de muitos outros críticos. A publicação da correspondência de Flaubert modificou a maneira como o autor era lido. E o quase mito do trabalho intenso e torturante do autor para burilar seus textos e buscar a palavra exata certamente contribuiu para que se modificassem os critérios de avaliação da literatura, particularmente da prosa romanesca. Se até meados do século XIX, a moral reinava como critério absoluto para que se decidisse quais eram os bons romances (MÜLLER, 2012), ao final do Oitocentos, era o fazer literário que passava a importar.

Se, por um lado, a modificação dos parâmetros que balizavam a avaliação de romances modificou a leitura de Flaubert (considerado imoral quando da publicação de seu primeiro romance, passou a ser visto como grande autor), por outro, é possível pensar que o próprio escritor contribuiu, sem saber ou planejar, para a alteração desses parâmetros. 0 processo de consagração de Flaubert na literatura francesa é contemporâneo do processo de consagração do gênero romanesco. Para Pierre Bourdieu, "Flaubert contribuiu para transformar o romance e para transformar a representação social do gênero, e em primeiro lugar entre seus pares" (BOURDIEU, 2005, p. 109). E a publicação da correspondência parece ter servido como o maior meio de divulgação de seu pensamento sobre a arte. 


\section{Referências}

ALTER EGO. Chronica estrangeira. Jornal do Commercio, Rio de Janeiro, 16 dez. 1892.

ARARIPE Junior. Obra crítica. Org. Afrânio Coutinho. Vol. 1. Rio de Janeiro: Ministério da Educação e Cultura: fundação Casa de Rui Barbosa, 1963.

ARARIPE Junior. Obra crítica. Org. Afrânio Coutinho. Vol. 2. Rio de Janeiro: Ministério da Educação e Cultura: fundação Casa de Rui Barbosa, 1960.

ARARIPE Junior. Obra crítica. Org. Afrânio Coutinho. Vol. 4. Rio de Janeiro: Ministério da Educação e Cultura: fundação Casa de Rui Barbosa, 1966.

BOURDIEU, Pierre. As regras da arte. Gênese e estrutura do campo literário. Trad. Maria Lúcia Machado. São Paulo: Companhia das Letras, 2005

CHILD, Theodore. Pariz litterario. Jornal do Commercio, Rio de Janeiro, 09 out. 1892.

CLÉROUX, Gilles. Correspondance de Gustave Flaubert. Bibliographie des éditions et des études. Rouen: Univ-Rouen, 2013. Disponível em: <flaubert.univ-rouen.fr $>$. Acesso em: 04 out. 2014

FLAUBERT, Gustave. Correspondance. Troisième série. Paris: Charpentier, 1891. Disponível em: <gallica.bnf.fr>. Acesso em: 25 nov. 2014.

FLAUBERT, Gustave. Correspondance. Quatrième série. Paris: Charpentier, 1893. Disponível em: <gallica.bnf.fr>. Acesso em: 25 nov. 2014.

FLAUBERT, Gustave. Correspondance. Nouvelle édition augmentée. Paris: Anversa Editions, s.d.

LACOSTE, Francis. La réception de Madame Bovary (1858-1882). Revue Flaubert. Rouen, n. 8, 2008. Disponível em: <flaubert.univ-rouen.fr>. Acesso em: 24 nov. 2014.

LECLERC, Yvan. Les éditions de La Correspondance de Flaubert. Rouen: Univ-Rouen, 2001. Disponível em: <flaubert.univ-rouen.fr>. Acesso em: 24 nov. 2014

MAUPASSANT, Guy de. Gustave Flaubert d'après ses lettres. Le Gaulois, Paris, 06 set. 1880. Disponível em: <gallica.bnf.fr>. Acesso em: 25 nov. 2014.

MÜLLER, Andréa Correa Paraiso. De romance imoral a obra-prima: trajetórias de Madame Bovary.2012. 346 f. Tese (Doutorado em Teoria e História Literária) - Instituto de Estudos da Linguagem, Universidade Estadual de Campinas, Campinas-SP, 2012.

PHILIPPOT, Didier. Gustave Flaubert: mémoire de la critique. Paris: Presses de l’Université Paris-Sorbonne, 2006
THIBAUDET, Albert. Une querelle littéraire sur le style de Flaubert. In: THIBAUDET, Albert. Réflexions sur la critique. 2 ed. Paris: Gallimard, 1939. Disponível em: <gallica. bnf.fr>. Acesso em: 27 nov. 2014.

Recebido em 20 de dezembro de 2015.

Aceito em 15 junho de 2015. 